\title{
RELATIVE IMPORTANCE OF TRADITIONAL RISK FACTORS FOR MALIGNANT MELANOMA IN THE CZECH POPULATION
}

\author{
Lucie Rajská1, 2 , Dana Göpfertová2, Jana Hercogová', Anna Jiráková1, Zuzana Sečníková1,2, Filip Rob', Zdeněk \\ Šmerhovský2 \\ ${ }^{1}$ Department of Dermatology and Venereology, 2nd Faculty of Medicine, Charles University and Bulovka Hospital, Prague, Czech Republic \\ 2Department of Epidemiology, 2nd Faculty of Medicine, Charles University, Prague, Czech Republic
}

\section{SUMMARY}

Aim: The Czech Republic is one of the leading European countries in incident cases of malignant melanoma (MM), which is on the rise. The study objective was to assess the strength of associations between MM and the known generally accepted risk factors for MM in the population of the Czech Republic.

Methods: The study was designed as a case-control study where cases were incident cases of MM detected at the Department of Dermatology and Venereology of the Bulovka Hospital. Controls were selected from cancer-free patients admitted to departments other than Dermatology and Venereology. Validated questionnaires were used to collect demographic, epidemiological, and clinical data.

Results: The binary logistic model shows the main risk factors for MM: male, female $(\mathrm{OR}=0.292,95 \% \mathrm{Cl}=0.175-0.486)$, a changed mole $(\mathrm{OR}=6.371,95 \% \mathrm{Cl}=3.774-10.756)$, a history of skin cancer $(\mathrm{OR}=95.704,95 \% \mathrm{Cl}=37.241-10.756)$, and sunbeds use $(\mathrm{OR}=3.594,95 \%$ $\mathrm{Cl}=1.288-10.028)$. Using sunscreen products was considered as a protective factor against $\mathrm{MM}(\mathrm{OR}=0.253,95 \% \mathrm{Cl}=0.137-0.466)$.

Conclusion: The primary and secondary prevention increasingly emerges as a public health priority in the effort to reverse the negative trend in cases of MM and mortality from this disease in the Czech Republic. A prerequisite for an effective secondary prevention through screening is, among others, the identification of the population groups at highest risk for MM.

Key words: incidence, malignant melanoma, risk factors, screening, questionnaire, case-control study

Address for correspondence: L. Rajská, Department of Dermatology and Venereology, 2nd Faculty of Medicine, Charles University and Bulovka Hospital, Budínova 2, 180 01, Prague, Czech Republic. E-mail: lucie.rajska@gmail.com

http://dx.doi.org/10.21101/cejph.a4569

\section{INTRODUCTION}

The incidence of malignant melanoma (MM) is on the rise worldwide, with a 5\% annual increase in patients newly diagnosed with melanoma. Melanoma is among the leading types of skin cancer. Unlike other skin cancers, it tends to metastasize rapidly to other organs. The most affected are the populations living in sunny countries such as New Zeland and Australia (1). The incidence of melanoma is higher in countries close to the Equator, but many cases also occur in Europe. The highest numbers of cases are reported in Switzerland, the Netherlands, Denmark, Norway, and Sweden (1-4). The prevalence of melanoma in the hispanic population of the USA is about six times lower than in the Caucasian population $(4,5)$. In the Afro-American population the prevalence is even twenty times lower (3). The epidemiological data show a constant $4-6 \%$ rise in incident cases of melanoma annually (6). In the Czech Republic, 2,044 cases of malignant melanoma (1,086 in males and 958 in females) were reported in 2011. Melanoma was the ninth most common cancer to be diagnosed in this country in $2012(7,8)$. The highest incidence of malignant melanoma in the years 2003-2011 in the Czech Republic was detected among men and women in Prague (9).
The increasing incidence of melanoma is often explained by improved diagnosis of early stages of this malignancy. Nevertheless, an expected proportional reduction in advanced stages of melanoma has not been observed and, therefore, the involvement of other factors should be considered. A possible explanation is low efficacy of melanoma screening in the Czech Republic, as it is not targeted at the population groups with the highest prevalence of melanoma.

The identification of the population group at the highest risk to be screened for melanoma should be based on the risk factors known to be associated with melanoma (10).

The highest number of both males and females diagnosed with melanoma are from the age group of 60-64 years (7). The most often reported risk factors for malignant melanoma are fair skin, fair hair and eyes, a family history of melanoma, immunosuppression, age, gender (females under 40 years of age and males over 40 years of age), multiple pigmented naevi, and excessive UV exposure (11-14).

As to the negative trend in melanoma, attention should be paid to the fact, among others, that the models derived from the observational epidemiological studies performed in the USA may not be generalizable to the European populations that are substantially more homogeneous than the American ones. In a homogeneous 
population where the individuals are more similar to each other in terms of the distribution of the risk factors, particular risk factors may vary in weight from those in a population which is ethnically heterogeneous (14-16). A case-control study was initiated in 2011 to test the strength of associations between the generally recognized risk factors listed above and the incidence of MM in the Czech population. The aim was to obtain data specific for the Czech population for use in both the primary and secondary prevention of MM.

\section{MATERIAL AND METHODS}

The study was designed as a case-control study. The cases were incident, histologically confirmed cases, diagnosed at the Department of Dermatology and Venereology of the Na Bulovce Hospital (NBH) between June 2011 and December 2014.

Controls were selected from other departments of the same hospital to obtain a ratio of two age-matched controls per case. The control inclusion criteria were age \pm 3 years in comparison with the case and absence of other malignancy. No other selection criterion was used.

The presence of the risk factors in the study participants was determined by clinical examination by a dermatologist using a validated questionnaire developed by the Euromelanoma Task Force of the European Academy of Dermatology and Venereology. The questionnaire contains specific questions targeted at the markers of UV exposure (staying in a sunny country for more than or less than one year when aged under 18 years or over 18 years, number of days spent in a sunny country as an adult, using sunbeds, etc.), hereditary factors (a family history of skin cancer, fair hair and eyes, etc.), and using sunscreen products while tanning or while sun exposed during other activity (16).

For each risk factor or protective factor, the odds ratio (OR) and $95 \%$ confidence interval were calculated and differences in the distribution of the risk factors between cases and controls at the bivariate level were tested by the chi-square test. For multivariate analysis, binary logistic regression was applied. All studied variables were used to develop the model. The stepwise procedure was applied with probability for entry set at 0.005 and the probability for removal of variables from the model at 0.10 . All tests were performed at a 5\% level of significance.

Binary logistic model on the base of multivariate analysis shows that the main risk factors for malignant melanoma are: skin cancer history, changes in moles and sunbed use.

The IBM SPSS Statistics 20.0 software was used for analyses.

\section{RESULTS}

Within this study, 174 cases of MM were identified and paired with 345 controls. At the bivariate level, the controls did not differ significantly from the cases in terms of age (mean age of 59.9 and 58.3 years, respectively, $\mathrm{p}=0.282$ ), education, a history of skin cancer in any relative, length of employment/outdoor employment, skin reactivity to solar radiation, getting severely sunburned at age under 18 years, staying in a sunny country, and using sunbeds (Table 1).

Table 1. Bivariate analysis of the results - nonsignificant results

\begin{tabular}{|c|c|c|c|c|}
\hline \multirow{2}{*}{ Questionnaire item } & \multirow{2}{*}{ OR } & \multicolumn{2}{|c|}{$95 \% \mathrm{Cl}$ for OR } & \multirow{2}{*}{$p$ value } \\
\hline & & Lower bound & Upper bound & \\
\hline Age (years) & 1.006 & 0.995 & 1.017 & 0.282 \\
\hline Family history of skin cancer & 0.582 & 0.165 & 2.055 & 0.401 \\
\hline Length of employment & & & & 0.199 \\
\hline 1 year or less & 2.037 & 0.645 & 6.433 & 0.225 \\
\hline $1-5$ years & 0.891 & 0.358 & 2.217 & 0.804 \\
\hline $6-10$ years & 0.157 & 0.020 & 1.210 & 0.076 \\
\hline 10 years or more & 1.405 & 0.767 & 2.574 & 0.271 \\
\hline Reactivity & & & & 0.126 \\
\hline Skin easy to get sunburned and difficult to get tanned & 1.896 & 0.547 & 6.572 & 0.313 \\
\hline Skin first sunburned and then tanned & 1.942 & 0.600 & 6.290 & 0.268 \\
\hline Skin sunburned a little and then tanned easily & 1.290 & 0.401 & 4.145 & 0.669 \\
\hline Skin easy to tan & 1.625 & 0.497 & 5.313 & 0.422 \\
\hline Not indicated & 4.469 & 1.054 & 18.938 & 0.042 \\
\hline Severely sunburned skin when aged under 18 years & & & & 0.690 \\
\hline Yes & 0.894 & 0.564 & 1.417 & 0.635 \\
\hline Do not remember & 0.794 & 0.450 & 1.402 & 0.426 \\
\hline Staying in a sunny country: & & & & 0.324 \\
\hline Yes - when aged under 18 years & 0.808 & 0.206 & 3.166 & 0.760 \\
\hline Yes - when aged over 18 years & 0.471 & 0.174 & 1.279 & 0.140 \\
\hline Sunbed user - yes & 1.290 & 0.547 & 3.041 & 0.561 \\
\hline Sunbed user - No. of years of sunbed use & 0.989 & 0.881 & 1.111 & 0.858 \\
\hline
\end{tabular}


Melanoma appeared to be statistically significantly associated with gender, with females being at lower risk of MM. At the bivariate level, MM was negatively associated with multiple pigmented naevi, skin cancer screening on request, using sunscreen products, and having a holiday in a sunny country. The results are summarized in Table 2.

Binary logistic model showed that at the level of multidimensional analysis, significant predictors of $\mathrm{MM}$ are variables concerning gender, changed mole, history of skin cancer, and sunscreen products and sunbeds use. The results are given in Table 3.

\section{DISCUSSION}

The aim of the study was to test the strength of associations between the generally recognized risk factors for $\operatorname{MM}(3,10)$ and the incidence of this disease in the relatively highly homogeneous
Czech Caucasian population as well as the usability of these factors to identify the population groups at highest risk for melanoma as target groups for screening. To collect data on exposure to risk factors, a validated questionnaire developed by the Euromelanoma Task Force of the European Academy of Dermatology and Venereology was used (17). In accordance with the initial assumption that the risk models derived from the experience of sunny countries with heterogeneous populations (18-22) may not be equally informative for the Czech population; at the bivariate level, no association was found between MM and some variables which are typical surrogate indicators of UV exposure such as length of outdoor employment (less than one year, 1-5 years, 5-10 years, or over 10 years), severe sunburn resulting in blisters at age under 18 years, long-term stay in a sunny country, or use of sunbeds. Neither was skin reactivity to solar radiation associated with MM in this study. In contrast to what is commonly believed, having a holiday in a sunny country appears to be a protective factor for MM, with an obvious biologi-

Table 2. Bivariate analysis of results - significant results $(p<0.05)$

\begin{tabular}{|c|c|c|c|c|}
\hline \multirow{2}{*}{ Questionnaire item } & \multirow{2}{*}{ OR } & \multicolumn{2}{|c|}{$95 \% \mathrm{Cl}$ for OR } & \multirow{2}{*}{$\mathrm{p}$ value } \\
\hline & & Lower bound & Upper bound & \\
\hline Gender: 1 for female & 0.380 & 0.261 & 0.552 & $<0.001$ \\
\hline Multiple pigmented naevi & 0.497 & 0.312 & 0.794 & 0.003 \\
\hline Changed mole & 2.489 & 1.708 & 3.629 & $<0.001$ \\
\hline History of skin cancer & 28.794 & 12.822 & 64.662 & $<0.001$ \\
\hline I want to get screened for skin cancer & 0.068 & 0.040 & 0.117 & $<0.001$ \\
\hline Screened for skin cancer in the past & 1.952 & 1.231 & 3.094 & 0.004 \\
\hline \multicolumn{5}{|c|}{ Sunscreen use while sun exposed more than hour } \\
\hline Sometimes & 0.333 & 0.207 & 0.534 & $<0.001$ \\
\hline Every time & 0.597 & 0.347 & 1.027 & 0.063 \\
\hline I never sunbathe & 1.127 & 0.591 & 2.149 & 0.716 \\
\hline \multicolumn{5}{|l|}{ Wearing sunscreen while sunbathing } \\
\hline Sometimes & 0.269 & 0.140 & 0.514 & $<0.001$ \\
\hline Every time & 0.452 & 0.240 & 0.850 & 0.014 \\
\hline I never sunbathe & 1.152 & 0.601 & 2.207 & 0.670 \\
\hline \multicolumn{5}{|l|}{ Number of weeks of summer holiday } \\
\hline 2 weeks or less & 0.730 & 0.467 & 1.139 & 0.165 \\
\hline More than 2 weeks & 0.332 & 0.194 & 0.569 & $<0.001$ \\
\hline
\end{tabular}

Table 3. Binary logistic model of associations between the incidence of suspected melanoma and risk factors in the participants of the European Day of Melanoma

\begin{tabular}{|c|c|c|c|c|}
\hline \multirow{2}{*}{ Simplest model } & \multirow{2}{*}{ OR } & \multicolumn{2}{|c|}{$95 \% \mathrm{Cl}$ for OR } & \multirow{2}{*}{$\mathrm{p}$ value } \\
\hline & & Lower bound & Upper bound & \\
\hline Gender: 1 for female & 0.292 & 0.175 & 0.486 & $<0.001$ \\
\hline Changed mole & 6.371 & 3.774 & 10.756 & $<0.001$ \\
\hline History of skin cancer & 95.704 & 37.241 & 245.947 & $<0.001$ \\
\hline \multicolumn{5}{|c|}{ Using sunscreen while sun exposed for more than hour } \\
\hline Sometimes & 0.253 & 0.137 & 0.466 & $<0.001$ \\
\hline Every time & 0.932 & 0.456 & 1.907 & 0.848 \\
\hline I never sunbathe & 0.854 & 0.377 & 1.936 & 0.706 \\
\hline Sunbed user & 3.594 & 1.288 & 10.028 & 0.015 \\
\hline
\end{tabular}


cal gradient where the risk for MM decreases with an increasing length of the holiday in a sunny country. On the other hand, using sunscreen products significantly reduces the risk for MM and individuals having a longer holiday in a sunny country might be more likely to protect themselves better from UV radiation.

A possible explanation for some unexpected observations can be joint effects of two or more factors, e.g. using sunscreen products while sun exposed, getting screened for skin cancer on request, or having been screened for skin cancer in the past. It follows that the risk assessment at the bivariate level on basis of the questions of the validated questionnaire can be misleading either due to modifying or confounding effects.

The binary logistic model showed that if mutual effects of specific variables from the validated questionnaire are taken into account, the variables considered as surrogate indicators of UV exposure are reduced to the protective effect of sunscreen products and risk from sunbed use. Another risk factor for MM is a changed mole, which increases the risk for MM about six times. A history of skin cancer is an extremely high risk factor, with an OR of 95.70 (95\% CI=37.24-245.95). The last variable that had an effect on MM is gender, with females being at lower risk for MM than males. From the binary logistic model, it clearly follows that some of the bivariate relationships are confounded (e.g. using sunbeds is not a statistically significant risk factor at the bivariate level) and that only two (using sunscreen products and using sunbeds) of the external factors characterizing UV exposure are relevant, and possibly also differences in behavioural patterns between males and females.

\section{CONCLUSION}

Of the 17 factors presented in the validated questionnaire developed by the Euromelanoma Task Force of the European Academy of Dermatology and Venereology, only five were identified as significant predictors of MM. This finding supports scepticism about the generalizability of some MM risk models to a homogeneous Caucasian population. It is not a negative criticism, but rather an attempt to open the discussion about the need for adjusting them to the Central European conditions. Of the directly applicable results of the present study, the risk from using sunbeds needs to be underlined. In this regard, the prevention should target human behaviour. Similarly, using sunscreen products was found to be effective in protecting from MM.

\section{Acknowledgement}

Supported by grant No IGA NT 12401 from the Internal Grant Agency of the Ministry of Health of the Czech Republic for the project Distribution of the risk factors for melanoma in the Czech population and their application to the primary prevention.

\section{Conflict of Interests}

None declared

\section{REFERENCES}

1. International Agency for Research on Cancer. Melanoma of skin ASR (W) per 100,000, all ages [Internet]. GLOBOCAN; 2012 [cited 2015 Nov
29]. Available from: http://globocan.iarc.fr/old/bar_sex_site.asp?selecti on $=16120 \&$ title $=$ Melanoma + of + skin $\&$ statistic $=2 \&$ populations $=6 \&$ win $\mathrm{dow}=1 \&$ grid $=1 \&$ color $1=5 \&$ color $1 \mathrm{e}=\&$ color $2=4 \&$ color $2 \mathrm{e}=\&$ submit $=\%$ C2\%A0Execute.

2. Tucker MA, Goldstein AM. Melanoma etiology: where are we? Oncogene. 2003 May 19;22(20):3042-52.

3. de Vries E, Bray FI, Coebergh JW, Parkin DM. Changing epidemiology of malignant cutaneous melanoma in Europe 1953-1997: rising trends in incidence and mortality but recent stabilizations in western Europe and decreases in Scandinavia. Int J Cancer. 2003 Oct 20;107(1):119-26.

4. Bränström R, Chang YM, Kasparian N, Affleck P, Tibben A, Aspinwall LG, et al. Melanoma risk factors, perceived threat and intentional tanning: an international online survey. Eur J Cancer Prev. 2010 May;19(3):216-26.

5. Rigel DS. Trends in dermatology: melanoma incidence. Arch Dermatol. 2010 Mar;146(3):318. doi: 10.1001/archdermatol.2009.379.

6. Hollestein LM, van den Akker SA, Nijsten T, Karim-Kos HE, Coebergh JW, de Vries E. Trends of cutaneous melanoma in The Netherlands: increasing incidence rates among all Breslow thickness categories and rising mortality rates since 1989. Ann Oncol. 2012 Feb;23(2):524-30.

7. Vojáčková N, Kružicová Z, Vrbová L, Sečníková Z.: Malignant melanoma. Ces Dermatovenerol. 2012;2(2):76-85. (In Czech.)

8. Zvolský M. Trends in incidence and mortality rates of malignant melanoma in the Czech Republic between 1980-2011. Aktuální informace ÚZIS [Internet]. 2014 [cited 2016 Nov 21];(11). Available from: http://uzis. cz/rychle-informace/vyvoj-incidence-mortality-zhoubneho-melanomuceske-republice-letech-1980-2011. (In Czech.)

9. Hamplová L. The report on the inhabitans helath of the Central Bohemian Region, Prague 2014. Prague: Krajská hygienická stanice Středočeského kraje se sídlem v Praze; 2014. (In Czech.)

10. Rajská L, Šmerhovský Z, Göpfertová D, Jiráková A, Sečníková Z, Rob F, et al. An example of the identification of risk factors and analysis of the data obtained during the European Day of Melanoma 2009. Ces Dermatovenerol. 2015;5(1):28-31. (In Czech.)

11. Williams LH, Shors AR, Barlow WE, Solomon C, White E. Identifying persons at highest risk of melanoma using self-assessed risk factors. J Clin Exp Dermatol Res. 2011;2(6). pii: 1000129.

12. Markovic SN, Erickson LA, Rao RD, Weenig RH, Pockaj BA, Bardia A, et al.; Melanoma Study Group of the Mayo Clinic Cancer Center. Malignant melanoma in the 21st century, part 1: epidemiology,risk factors, screening, prevention, and diagnosis. Mayo Clin Proc. 2007 Mar;82(3):364-80.

13. van der Leest RJ, de Vries E, Bulliard JL, Paoli J, Peris K, Stratigos AJ, et al. The Euromelanoma skin cancer prevention campaign in Europe: characteristics and results of 2009 and 2010. J Eur Acad Dermatol Venereol. $2011 \mathrm{Dec} ; 25(12)$ :1455-65.

14. Harbauer A, Binder M, Pehamberger H, Wolff K, Kittler H. Validity of an unsupervised self-administered questionnaire for self-assessment of melanoma risk. Melanoma Res. 2003 Oct;13(5):537-42.

15. Vojáčková N, Kružicová Z, Vrbová L, Hercogová J. Follow-up of patients with malignant melanoma. Cesk Dermatol. 2011;86(3):144-7. (In Czech.)

16. Psaty EL, Scope A, Halpern AC, Marghoob AA. Defining the patient at high risk for melanoma. Int J Dermatol. 2010 Apr;49(4):362-76.

17. Stratigos AJ, Forsea AM, van der Leest RJ, de Vries E, Nagore E, Bulliard JL, et al. Euromelanoma: a dermatology-led European campaign against nonmelanoma skin cancer and cutaneous melanoma. Past, present and future. Br J Dermatol. 2012 Aug;167 Suppl 2:99-104.

18. American Cancer Society. Cancer facts \& figures 2015. Atlanta: American Cancer Society; 2015.

19. Gandini S, Sera F, Cattaruzza MS, Pasquini P, Abeni D, Boyle P, et al. Meta-analysis of risk factors for cutaneous melanoma: I. Common and atypical naevi. Eur J Cancer. 2005 Jan;41(1):28-44.

20. Watts CG, Dieng M, Morton RL, Mann GJ, Menzies SW, Cust AE. Clinical practice guidelines for identification, screening and follow-up of individuals at high risk of primary cutaneous melanoma: a systematic review. Br J Dermatol. 2015 Jan;172(1):33-47.

21. Fears TR, Sagebiel RW, Halpern A, Elder DE, Holly EA, Guerry D 4th, et al. Sunbeds and sunlamps: who used them and their risk for melanoma. Pigment Cell Melanoma Res. 2011 Jun;24(3):574-81.

22. Lebbé C, Robert C, Ricard S, Sassolas B, Grange F, Saiag P, et al Evolution of sun-protection measures for children. J Eur Acad Dermatol Venereol. 2015 Feb;29 Suppl 2:20-2. 